\title{
Impacto de los residuos de ivermectina en los procesos tecnológicos de la leche y sus derivados
}

\author{
Iezzi, S.; Lifschitz, A.; Sallovitz, J.M.; Lanusse, C.; Imperiale, F. \\ Laboratorio de Farmacología, CIVETAN-CONICET, Facultad de Ciencias Veterinarias, UNCPBA, \\ (7000) Tandil, Argentina, T 0249-4439850. Mail: siezzi@vet.unicen.edu.ar
}

\begin{abstract}
Resumen
Iezzi, S.; Lifschitz, A.; Sallovitz, J.M.; Lanusse, C.; Imperiale, F.: Impacto de los residuos de ivermectina en los procesos tecnológicos de la leche y sus derivados. Rev. vet. 26: 2, 93-98, 2015. Se evaluó la estabilidad química de los residuos de ivermectina (IVM, fármaco antiparasitario) en leches bovina y ovina. La estabilidad del fármaco se midió mediante cromatografía liquida de alta performance analizando muestras de leche con residuos de IVM antes y después del tratamiento térmico. Además se evaluó, mediante la prueba del yogur y estudios microbiológicos de recuento de bacterias lácticas, el efecto de los residuos sobre la viabilidad de las bacterias ácido lácticas. Los residuos de IVM en leche demostraron ser estables a los tratamientos térmicos utilizados en la industria láctea de pasteurización: baja temperatura/largo tiempo (LTLT $65^{\circ} \mathrm{C}, 30 \mathrm{~min}$ ) y alta temperatura/corto tiempo (HTST $75^{\circ} \mathrm{C}, 15 \mathrm{~s}$ ). Los procesos de industrialización de la leche basados en la actividad de las bacterias lácticas tampoco fueron afectados por la presencia de residuos de IVM. Las concentraciones evaluadas no modificaron el incremento de la acidez en la prueba del yogur y no disminuyeron los recuentos de bacterias lácticas presentes en muestras de yogures elaborados con residuos del antiparasitario. El impacto de los residuos de fármacos antiparasitarios en los procesos tecnológicos de elaboración de alimentos y en la salud del consumidor a largo plazo debe ser cuidadosamente analizado.
\end{abstract}

Palabras clave: leche, residuos de ivermectina, estabilidad térmica, fermentación acido láctica, bacterias ácido lácticas.

\begin{abstract}
Iezzi, S.; Lifschitz, A.; Sallovitz, J.M.; Lanusse, C.; Imperiale, F.: Impact of ivermectin residues in the technological processes of milk and its derivatives. Rev. vet. 26: 2, 9398, 2015. Chemical stability of ivermectin residues (IVM, antiparasitic drug) in cattle and sheep milk was evaluated. IVM residues were measured in milk samples before and after heat treatment by high performance liquid chromatography. Additionally, the effect of drug residues on the lactic acid fermentation was assessed by testing the viability and counts of lactic acid bacteria. IVM concentrations in milk were stable after standard procedures used in dairy industry LTLT pasteurization $\left(65^{\circ} \mathrm{C}, 30 \mathrm{~min}\right)$ and $\operatorname{HTST}\left(75^{\circ} \mathrm{C}, 15 \mathrm{~s}\right)$. Industrial milk processing based on the activity of lactic acid bacteria was not affected by the presence of IVM residues. IVM concentrations did not affect the increment of acidity nor the number of lactic acid bacteria in yogurt samples. The impact of the residues of antiparasitic drugs in technological processes of food processing and consumer health must be carefully analyzed to avoid long-term consequences.
\end{abstract}

Key words: milk, ivermectin residues, thermal stability, lactic acid fermentation, lactic acid bacteria.

\section{INTRODUCCIÓN}

Actualmente se conocen numerosos fármacos veterinarios capaces de dejar residuos en leche y prácticamente no existen animales que no hayan recibido algún tipo de producto quimioterápico en alguna etapa de su

Recibido: 21 mayo 2015 / Aceptado: 30 junio 2015 vida. Por lo tanto, los consumidores están potencialmente expuestos a ingerir residuos de sustancias que pueden inducir cierto grado de toxicidad aguda o crónica ${ }^{12}$.

La presencia de residuos de medicamentos en leche puede tener efectos negativos sobre la salud pública ${ }^{3}$. Por otra parte, los residuos químicos, particularmente compuestos antimicrobianos (penicilina, cloxacilina, clorhidrato de tetraciclina y estreptomicina) pueden retrasar o 
alterar los procesos bacteriológicos utilizados en la fabricación de determinados productos lácteos como el yogur y el queso ${ }^{2}$.

Las bacterias ácido lácticas son gérmenes Gram positivos que producen ácido láctico como resultado de la fermentación de hidratos de carbono. Están normalmente presentes en la leche y también se utilizan como cultivos iniciadores en la elaboración de productos lácteos fermentados como el yogur. Las bacterias ácido lácticas juegan un papel crucial en la producción de alimentos fermentados como verduras, carnes y -especialmente- productos lácteos.

Los fármacos antiparasitarios son agentes quimioterapéuticos utilizados ampliamente en la práctica veterinaria para controlar los parásitos del ganado ${ }^{11}$. Las ventajas productivas del tratamiento de animales productores de leche con antihelmínticos, ha sido ampliamente documentada ${ }^{8,10}$. Entre estos compuestos, sólo un número limitado está autorizado para ser utilizado durante el período de lactancia ${ }^{6}$.

La ivermectina (IVM) es una lactona macrocíclica de amplio espectro que posee características farmacológicas ideales para el control de las parasitosis internas y externas. Si bien su empleo no está recomendada para animales en período de lactancia, su uso "extra marbete" para el tratamiento de parasitosis en bovinos y ovinos lecheros es una práctica muchas veces utilizada en diferentes explotaciones. Esta situación plantea la necesidad de estudiar si las ventajas de utilización de este fármaco en el tratamiento de las parasitosis en animales en lactación son compatibles con la calidad higiénico-sanitaria de la leche y la seguridad del consumidor.

Son pocos los estudios realizados sobre las concentraciones de residuos de fármacos en alimentos sometidos a procesos tecnológicos de elaboración como pasteurización, congelación y cocción. La estabilidad térmica de las lactonas macrocíclicas fue evaluada en leche ovina sometida a diferentes temperaturas ${ }^{4}$. Sin embargo, resulta importante profundizar los conocimientos sobre el impacto de estos fármacos sobre los procesos de fermentación ácido láctica, especialmente cuando la industrialización de la leche se basa en la calidad de los procesos de fermentación ácida. Por otra parte, resulta necesario indagar el efecto que pueden tener estas drogas sobre la cantidad y morfología de las bacterias ácido lácticas.

En consecuencia, los objetivos de este trabajo fueron: a) evaluar la estabilidad de las concentraciones residuales de IVM en leche cruda de vaca y oveja sometidas a pasteurización a baja temperatura/largo tiempo y a alta temperatura/corto tiempo; b) evaluar los efectos de diferentes concentraciones de IVM sobre la fermentación ácido láctica de las bacterias en leches de vaca y oveja mediante el test de la prueba de yogur, y c) evaluar la viabilidad de las bacterias lácticas obtenidas de yogures elaborados a partir de leches de vaca y oveja con residuos de IVM, realizando un recuento en placa de las bacterias lácticas y evaluando la morfología de las bacterias por microscopía electrónica de barrido.

\section{MATERIAL Y MÉTODOS}

Evaluación de la estabilidad térmica de los residuos de IVM en leche. Para la preparación de la leche sin tratamiento térmico, muestras sin residuos del fármaco $(1 \mathrm{ml})$ fueron obtenidas de vacas y ovejas lactantes y fueron fortificadas con IVM $(1,5$ y $10 \mathrm{ng} / \mathrm{ml}$ patrón de referencia), siendo utilizadas para validar el método de cromatografía líquida de alta performance (HPLC). Soluciones patrón de IVM se prepararon por diluciones sucesivas en metanol a partir de una solución madre de $1 \mathrm{mg} / \mathrm{ml}$. Las muestras de leche fortificadas fueron adicionadas con abamectina (ABM) como estándar interno de IVM.

Preparación de muestras con tratamientos térmicos. Muestras de leche de vaca y oveja sin residuos del fármaco fueron fortificadas con IVM $(1-10 \mathrm{ng} / \mathrm{ml})$ y sometidas a tratamiento térmico (pasteurización) a baja temperatura/largo tiempo $\left(65^{\circ} \mathrm{C}, 30 \mathrm{~min}, \mathrm{LTLT}\right) \mathrm{o}$ a alta temperatura/corto tiempo $\left(75^{\circ} \mathrm{C}, 15 \mathrm{~s}\right.$, HTST) en un baño térmico de laboratorio. En cada procedimiento la temperatura de las muestras fue monitoreada durante todo el proceso, con un termómetro de mercurio inmerso en el interior de la muestra de leche. Finalizado el tiempo de exposición, la temperatura de las muestras fue reducida rápidamente en baño de agua fría a $4^{\circ} \mathrm{C}$. Las muestras tratadas térmicamente y no tratadas, fueron suplementados con estándar interno y analizadas por HPLC.

También se prepararon controles (muestras de leche sin droga), los cuales fueron sometidos a la misma temperatura que las muestras experimentales con el fin de descartar la posibilidad de la presencia de interferencias endógenas en el tiempo de retención de IVM durante la corrida cromatográfica.

Análisis de las concentraciones de IVM en leche por HPLC. Los procedimientos de extracción y las condiciones cromatográficas para la cuantificación de IVM en muestras de leche de vaca y oveja se llevaron a cabo siguiendo técnicas propias descritas previamente (J Agric Food Chem 52: 6205-6211, 2004). Antes de analizar las muestras experimentales se realizó una validación completa de los procedimientos analíticos para la extracción y cuantificación de IVM en leche de vaca y oveja.

Las concentraciones del fármaco en las muestras experimentales se determinaron por HPLC calculando la relación entre las áreas bajo los picos de IVM y su estándar interno (ABM) usando el Software de Clase LC 10, versión 1.2, y la interpolación de estas áreas en las líneas de calibración realizadas en leche. Se utilizó el programa estadístico Instat 3,0 (Graph Pad Software Inc., San Diego, CA, EE.UU.) para el análisis de regresión lineal y pruebas de linealidad. Se empleó la prueba $t$ de Student para estimar las diferencias entre las concentraciones de fármaco obtenidas en muestras de leche sin tratar y tratadas térmicamente. Un $\mathrm{p}<0,05$ fue considerado como estadísticamente significativo. 
Evaluación de los procesos de fermentación acido láctica. La "prueba del yogur" o test de inhibición del yogur ${ }^{7}$ se utilizó para determinar cualitativamente la presencia de sustancias inhibidoras en leche. Esta prueba se basa en la coagulación ácida, donde la producción de ácido láctico a partir de la fermentación bacteriana (bacterias lácticas) se traduce en acidificación del medio. La prueba pone de manifiesto la capacidad de ciertas sustancias (inhibidoras) para suprimir parcial o totalmente la actividad normal de las bacterias lácticas, lo cual se traduce en ausencia de aumento de acidez de la leche.

Preparación de muestras experimentales - Muestras de leche. Leche en polvo (La Serenísima ${ }^{\circledR}$, Argentina, lote 4128) fue reconstituida antes de ser utilizada con $10 \%$ de agua destilada estéril. La leche reconstituida libre de sustancias inhibitorias (leche blanco) fue fraccionada $(10 \mathrm{ml})$ en tubos estériles.

Cultivo bacteriano. El cultivo iniciador fue preparado en condiciones de esterilidad, inoculando la leche reconstituida con un 2-3\% de cultivo activo de yogur (mezcla de Steptococcus thermophilus y Lactobacillus bulgaricus) e incubándolo en un baño de agua a $45^{\circ} \mathrm{C}$ durante $2 \mathrm{~h} 30 \mathrm{~min}$. Luego del período de incubación y para verificar que el cultivo fuese activo, se procedió a medir la acidez. El cultivo bacteriano fue considerado activo con un valor de acidez entre 18 y 25 grados Soxhlet-Henkel ( $\left.{ }^{\circ} \mathrm{SH}\right)$.

Este aumento de acidez favorece la coagulación de la leche en el tiempo establecido y a una temperatura adecuada. Una vez confirmada la actividad del cultivo, fue diluido con agua estéril $(1: 1, \mathrm{v} / \mathrm{v})$, homogeneizado y adicionado a las muestras control (sin droga) y experimentales de leche bovina/ovina (adicionadas con IVM).

Procedimiento experimental. Diez (10) $\mathrm{ml}$ de leche bovina/ovina blanco (sin droga) con $0,5 \mathrm{ml}$ de cultivo bacteriano activo diluido, fueron adicionadas con diferentes concentraciones de IVM $(5,20,50,100$ y $1000 \mathrm{ng} / \mathrm{ml})(\mathrm{n}=3)$. Para corroborar si el solvente metanol (utilizado para preparar las soluciones estándares de IVM) actuaba como inhibidor del crecimiento bacteriano de la leche, fue necesario adicionar metanol (volumen semejante al utilizado) a las muestras que contenían $10 \mathrm{ml}$ de leche bovina/ovina blanco y $0,5 \mathrm{ml}$ de cultivo activo de yogurt diluido $(\mathrm{n}=3)$.

La acidez de las muestras de leche ( $\left.{ }^{\circ} \mathrm{SH}\right)$ se determinó por método colorimétrico. Se añadió una solución alcohólica $2 \%$ de fenolftaleína a la muestra de leche. Luego se adicionó $\mathrm{NaOH}$ y se agitó hasta visualizar un color rosado en la muestra lo que se tomó como una indicación de neutralidad. El cálculo de ${ }^{\circ} \mathrm{SH}$ se hizo dividiendo el volumen $(\mathrm{ml})$ de $\mathrm{NaOH}$ necesario para alcanzar la neutralidad por un factor de 0,25 de la siguiente manera: ${ }^{\circ} \mathrm{SH}=\mathrm{ml}$ de $\mathrm{NaOH} / 0,25$.

Antes y después de la incubación, se midió la acidez de cada muestra. El valor de incremento de acidez (en $\left.{ }^{\circ} \mathrm{SH}\right)$ fue utilizado como indicador de la actividad del cultivo bacteriano. Este valor fue estimado restando al valor de acidez final el valor de acidez inicial obtenido para cada muestra de leche. Posteriormente los valores de incremento de acidez obtenidos en las muestras experimentales (con droga) fueron comparados con los obtenidos en las muestras de leche control (sin droga).

$\mathrm{Si}$ el incremento de la acidez de las muestras de ensayo estaba por encima de la mitad del aumento de la acidez de las muestras control, después del tiempo de incubación ( 2 h $30 \mathrm{~min}$ ), se consideró que la presencia de las sustancia bajo evaluación (IVM y metanol) no poseían actividad inhibidora. Se utilizó la prueba t de Student para estimar las diferencias entre los incrementos de acidez obtenidos en el control y las muestras de leche enriquecidas ( $p<0,05$ valor fue considerado como estadísticamente significativo).

Recuento microbiológico y aislamiento de bacterias lácticas. Leches bovina y ovina fueron sometidas a pasteurización LTLT, enfriadas $\left(45^{\circ} \mathrm{C}\right)$ y se les añadió cultivo activo diluido $(0,5 \mathrm{ml})$. Luego se adicionaron diferentes concentraciones de IVM (rango 5-1000 ng/ $\mathrm{ml})$. Por otra parte muestras de leche blanco $(10 \mathrm{ml})$ se enriquecieron con metanol (rango de 50 a $200 \mu \mathrm{l}$ ) más $0,5 \mathrm{ml}$ de cultivo activo diluido, para corroborar al igual que lo realizado en la prueba de yogur, si el solvente metanol (utilizado para preparar las soluciones estándares de IVM) actuaba como inhibidor del crecimiento bacteriano de la leche. La totalidad de las muestras se incubó en baño de agua a $45^{\circ} \mathrm{C}, 2 \mathrm{~h} 30 \mathrm{~min}$.

Las muestras de yogur obtenidas se conservaron entre 4 y $8^{\circ} \mathrm{C}$ durante $12 \mathrm{~h}$ antes del cultivo en placas. Posteriormente se realizó el recuento de bacterias lácticas termófilas presentes en los yogures controles, yogures adicionados con IVM y yogures adicionados con metanol en placa de agar leche después de $48 \mathrm{~h}$ de incubación a $37^{\circ} \mathrm{C}$ en condiciones de microaerofilia, según técnica convencional ${ }^{9}$. Los recuentos se realizaron por triplicado.

Por otra parte, se realizó un recuento de bacterias coliformes en agar VRB (violeta rojo bilis, FIL-IDF 1966) ${ }^{7}$, verificando de esta manera la correcta pasteurización de las muestras de leche. Las características fenotípicas de las bacterias se examinaron por microscopia de contraste de fase. Se utilizó la prueba t de Student para estimar la diferencia entre el número de colonias de las muestra control y las muestras de yogur adicionadas con IVM y metanol. Fue considerado como valor estadísticamente significativo $\mathrm{p}<0,05$.

Observación de bacterias lácticas por microscopia electrónica de barrido. Adicionalmente, se realizaron estudios de ultraestructura de las bacterias lácticas con microscopio electrónico de barrido. Se estudiaron bacterias obtenidas de muestras de yogur elaborados a partir de leche bovina y ovina sin fármaco (control) y con IVM (100 ng/ml). Después de $48 \mathrm{~h}$ de incubación en agar leche a $37^{\circ} \mathrm{C}$ en condiciones de microaerofilia, se recogieron las colonias de bacterias lácticas y se evaluaron a través de un microscopio electrónico de barrido EVO 40VP con un voltaje de aceleración de $7 \mathrm{kV}$. Las muestras de yogur obtenidas se procesaron siguiendo una técnica de preparado para observación 
en microscopia electrónica de barrido modificando las etapas de deshidratación ${ }^{1}$. Los criterios para la evaluación de la viabilidad de bacterias lácticas incluyeron la observación ultraestructural de la pared de bacterias ácido lácticas obtenidas de una muestra de yogur elaborado con leche adicionada con IVM comparando con una muestra de control (yogur elaborado con leche sin residuos del fármaco).

\section{RESULTADOS}

Después de someter las muestras de leche a los tratamientos térmicos, en los cromatogramas de las muestras de leche adicionadas con IVM y de leche blanco, no se observaron productos metabólicos de la degradación de IVM, descartando cualquier posible interferencia endógena en sus tiempos de retención.

Los resultados para cada tratamiento térmico se enunciaron como la diferencia expresada como porcentaje entre la concentración promedio de IVM recuperada en leche después del tratamiento térmico, respecto de la concentración promedio de IVM recuperada en muestras de leche sin tratamiento térmico.

Los porcentajes obtenidos a partir de estas diferencias se ubicaron en el rango de $-3,21$ a 3,45\% (Tabla 1). Sin embargo. estas variaciones no fueron estadísticamente significativas $(p>0,05)$ y estuvieron dentro del rango de variación del método analítico empleado.

Tabla 1. Efecto del tratamiento térmico sobre la estabilidad de los residuos de ivermectina en leche de ambas especies.

\begin{tabular}{|c|c|c|c|}
\hline especie & $\begin{array}{l}\text { tratamiento } \\
\text { térmico }\end{array}$ & $\begin{array}{c}\text { concentración } \\
(\mathrm{ng} / \mathrm{ml})\end{array}$ & $\begin{array}{c}\text { diferencias } \\
\text { (en \%)* }\end{array}$ \\
\hline \multirow{8}{*}{$\begin{array}{l}\text { leche } \\
\text { bovina }\end{array}$} & \multirow{4}{*}{$\begin{array}{l}65^{\circ} \mathrm{C}, 30 \mathrm{~min} \\
\text { LTLT }\end{array}$} & 1 & 2,73 \\
\hline & & 5 & $-0,14$ \\
\hline & & 10 & 0,10 \\
\hline & & $\bar{x}$ & 0,90 \\
\hline & \multirow{4}{*}{$\begin{array}{l}75^{\circ} \mathrm{C}, 15 \mathrm{~s} \\
\mathrm{HTST}\end{array}$} & 1 & $-2,11$ \\
\hline & & 5 & $-1,26$ \\
\hline & & 10 & 0,43 \\
\hline & & $\bar{x}$ & $-0,98$ \\
\hline \multirow{8}{*}{$\begin{array}{l}\text { leche } \\
\text { ovina }\end{array}$} & \multirow{4}{*}{$\begin{array}{l}65^{\circ} \mathrm{C}, 30 \mathrm{~min} \\
\text { LTLT }\end{array}$} & 1 & 3,45 \\
\hline & & 5 & 1,03 \\
\hline & & 10 & 1,05 \\
\hline & & $\bar{x}$ & 1,84 \\
\hline & \multirow{4}{*}{$\begin{array}{l}75^{\circ} \mathrm{C}, 15 \mathrm{~s} \\
\text { HTST }\end{array}$} & 1 & $-3,10$ \\
\hline & & 5 & 0,32 \\
\hline & & 10 & $-3,21$ \\
\hline & & $\bar{x}$ & $-2,00$ \\
\hline
\end{tabular}

$\overline{\mathrm{X}}=$ media aritmética. LTLT: pasteurización a baja temperatura/largo tiempo; HTST: pasteurización a alta temperatura/ corto tiempo. $\left(^{*}\right)$ diferencias de las concentraciones residuales de ivermectina-IVM (los valores se obtuvieron de la diferencia entre la concentración promedio de IVM recuperada en leche después del tratamiento térmico respecto de la concentración promedio de IVM recuperada en muestras de leche sin tratamiento térmico.
Tampoco se observaron diferencias entre los resultados obtenidos para las leches de ambas especies de rumiantes.

Ningún producto metabólico ni de degradación fue detectado en las corridas cromatográficas correspondientes a las muestras sometidas a tratamiento térmico. Estos resultados demuestran que no hubo cambios químicos, que dieran origen a nuevos compuestos tras la exposición de la leche con IVM a los tratamientos térmicos empleados.

El incremento de la acidez de las muestras de leches bovina y ovina adicionadas con IVM (rango: 5 a $1000 \mathrm{ng} / \mathrm{ml}$ ) estuvieron por encima de la mitad del valor de incremento de acidez observada en las muestras de leche control (sin residuos). Además, se evaluó la influencia de los diferentes volúmenes de metanol (rango de 50 a $200 \mu$ l) sobre la fermentación ácido láctica en leches bovina y ovina. A partir de esta evaluación, se determinó que un volumen de metanol $>$ a $100 \mu 1$ afecta a la coagulación de la leche incubándola a $45^{\circ} \mathrm{C}$ durante $2 \mathrm{~h} 30 \mathrm{~min}$. Por lo tanto, la cantidad de solución de fármaco añadido a una muestra de leche nunca excedió un volumen de $100 \mu \mathrm{l}$ de metanol.

Por otra parte, se elaboró yogur bovino y ovino con cultivos de bacterias ácido lácticas como Lactobacillus delbrueckii ssp. bulgaricus y Streptococcus thermophilus con leche adicionada con IVM (rango de 5-1000 $\mathrm{ng} / \mathrm{ml}$ ) por triplicado. El recuento de bacterias lácticas de muestras de yogures se realizó en medio agar leche luego de la incubación microaerófila a $37^{\circ} \mathrm{C}$ durante $48 \mathrm{~h}$. Los recuentos de bacterias lácticas a partir de muestras de yogures bovino y ovino elaborados con leche adicionada con IVM oscilaron entre $6,93 \times 10^{8} \mathrm{y}$ $8,37 \times 10^{8}$ unidades formadoras de colonias / mililitro (UFC/ml), con un promedio de $7,73 \times 10^{8} \pm 0,81$ (yogur bovino) y $8,01 \times 10^{8} \pm 0,62 \mathrm{UFC} / \mathrm{ml}$ (yogur ovino), como indica la Figura 1.

Los recuentos de bacterias lácticas a partir de muestras de yogures elaborados con residuos de IVM no fueron estadísticamente diferentes a las muestras control. Además, las muestras de yogur de control positivo adicionadas con penicilina $(4 \mu \mathrm{g} / \mathrm{l})$ dio como resul-

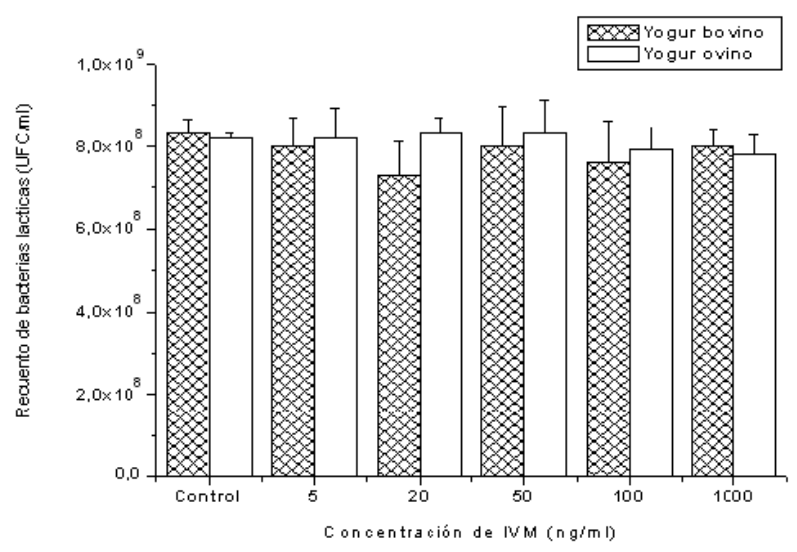

Figura 1. Comparación de recuentos de bacterias lácticas de yogures elaborados con leche bovina y ovina con residuos de ivermectina (IVM). 

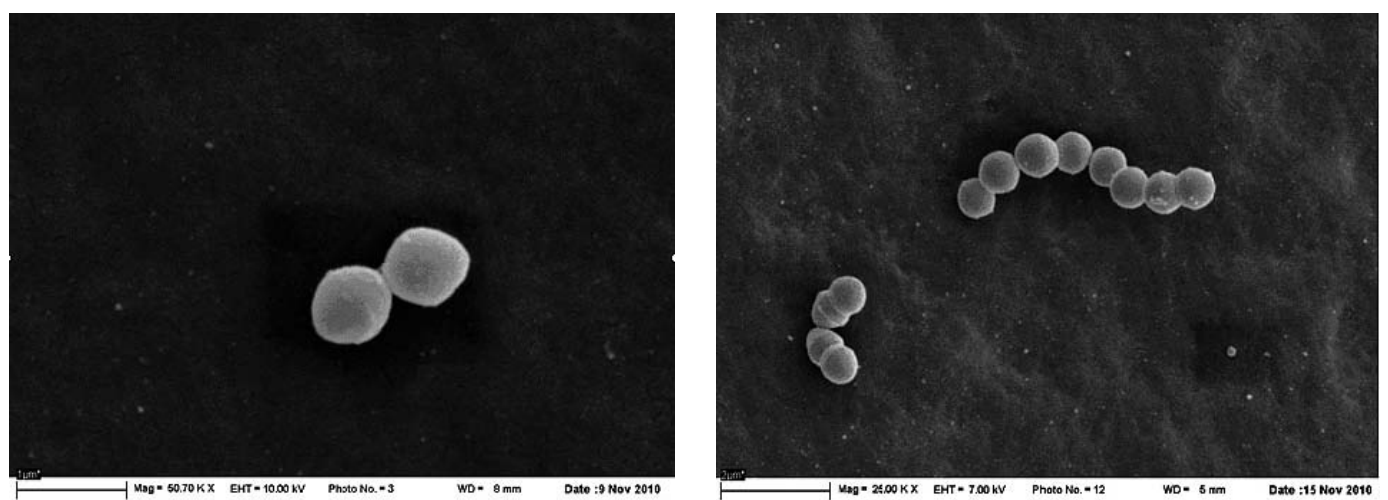

Figura 2. Cocos aislados de yogur elaborado sin residuos de ivermectina (izquierda) y yogur enriquecido con ivermectina $100 \mathrm{ng} / \mathrm{ml}$ (derecha).

tado un recuento inferior de bacterias lácticas $\left(3,4 \times 10^{8}\right.$ $\mathrm{UFC} / \mathrm{ml})$ y estadísticamente diferentes $(\mathrm{p}<0,05)$ a la muestra de control libre de drogas $\left(6,6 \times 10^{8} \mathrm{UFC} / \mathrm{ml}\right)$.

La integridad estructural de las bacterias lácticas se evaluó por microscopía electrónica de barrido de muestras de yogur control, yogur elaborado a partir de leche bovina con residuos de IVM $(100 \mathrm{ng} / \mathrm{ml})$ y yogur elaborado a partir de leche ovina con residuos de IVM $(100 \mathrm{ng} / \mathrm{ml})$. Los estudios ultraestructurales no revelaron cambio en la estructura de las bacterias lácticas de ambas muestras (Figura 2).

\section{DISCUSIÓN}

En los estudios de la estabilidad térmica de IVM en leches bovina y ovina, las concentraciones adicionadas en leche fueron las detectadas en bovinos y ovinos tratados con IVM, en estudios in vivo realizados anteriormente ${ }^{14}$. Además, los procesos térmicos estudiados en este trabajo son los más utilizados en la industria láctea: $75^{\circ} \mathrm{C}$ durante $15 \mathrm{~s}$ (HTST) y $65^{\circ} \mathrm{C}$ durante 30 min (LTLT). Del mismo modo que se demostró en este estudio, otros investigadores demostraron que los diferentes procesos de calentamiento estudiados $\left(74^{\circ} \mathrm{C} 40\right.$ $\mathrm{s}, 80^{\circ} \mathrm{C} 1 \mathrm{~min}, 100^{\circ} \mathrm{C} 10 \mathrm{~s}, 65^{\circ} \mathrm{C} 30 \mathrm{~min}, \mathrm{y} 75^{\circ} \mathrm{C} 15 \mathrm{~s}$ ) no afectaron las concentraciones de IVM en leche de oveja $^{4}$.

Por otra parte, los residuos de IVM en diferentes tejidos de animales, tales como músculos e hígado, también fueron estables bajo condiciones de cocción (horno de microondas, freído, hervido) y las pérdidas de IVM observadas fueron detectadas en el fluido de cocción $^{5,13}$.

Los resultados aquí obtenidos mediante la prueba de yogur ${ }^{7}$ determinaron que la presencia de IVM en leches bovina y ovina no tiene un efecto sobre la actividad de las bacterias lácticas, incluso después de evaluar concentraciones superiores a las medidas en anteriores estudios propios in vivo (J Agric Food Chem 52: 6205$6211,2004)$. Esto tiene trascendencia teniendo en cuenta la existencia en el mercado farmacéutico veterinario de formulaciones concentradas que se aplican a dosis superiores. Por lo tanto la presencia de mayores resi- duos en leche no afectan el procesamiento industrial, llegando intactas al consumidor.

Como se demuestra en la Figura 2, la morfología de las bacterias lácticas no se vio afectada por la presencia de residuos de IVM. Datos previos disponibles muestran un efecto diferente del fármaco en la estructura de parásitos como Echinoccoccus granulosus incubados con IVM $(1 \mathrm{mg} / \mathrm{ml})$. Se observaron alteraciones a nivel del tegumento y la presencia de grandes vacuolas a nivel citoplasmático. Sin embargo, las bacterias lácticas no se vieron afectadas por la presencia de IVM, verificando lo corroborado en la prueba de fermentación y los recuentos de bacterias.

En el sistema actual de producción de ganado, la optimización de la productividad depende en gran medida de la utilización de compuestos farmacológicamente activos. El uso de medicamentos en animales productores de alimentos es importante para la salud de los animales, pero las ventajas de la utilización de los compuestos químicos en la producción ganadera siempre deben evaluarse en función de su riesgo para los consumidores. Muchos compuestos antiparasitarios están aprobados para el tratamiento de enfermedades parasitarias en los animales productores de alimentos. Sin embargo, sólo un número limitado de formulaciones comerciales están autorizados para el tratamiento de los animales durante el período de lactancia.

La resistencia generalizada de los nematodos a diferentes grupos antihelmínticos ha llevado a situaciones de un uso extra-marbete por parte de los productores de compuestos antiparasitarios en explotaciones lecheras ovina y bovina. Por lo tanto, existe una preocupación por la posible presencia de residuos de medicamentos detectables en la leche y productos lácteos. Esta inquietud involucra no solamente a los riesgos para la salud, sino también a las restricciones en el comercio internacional.

En la leche de bovinos y ovinos, los residuos de IVM son estables a los tratamientos térmicos convencionales más utilizados en la industria láctea. Los procesos industriales basados en la fermentación ácido láctica no se ven afectados por la presencia de estos residuos en la leche, lo que indica que la prueba de yogur 
no es adecuada para detectar cualitativamente concentraciones residuales de estas moléculas.

El uso racional de los medicamentos antiparasitarios en los sistemas de producción de leche es esencial para un suministro de alimentos más seguros para el consumo global. De acuerdo con los organismos mundiales de referencia, la presencia de residuos de fármacos en alimentos de origen animal son considerados como un factor de riesgo en la salud pública y como limitante en el desarrollo económico de cualquier país.

\section{REFERENCIAS}

1. Alippi A. 1992. Detección de Bacillus larvae en poblaciones mixtas de esporas bacterianas a partir de restos larvales. Microbiología 8: 115-118.

2. Berruga MI, Noves B, Molina MP, Roman M, Molina A. 2008. Influence of cephalosporins on the coagulation time of yogurt made from ewes'milk. Int J Dairy Tech 61: 372-378.

3. Botsoglou NA, Fletouris DJ. 2001. Consumer perceptions and concerns, drug residues in food. In: Pharmacology, food safety and analysis (Marcel Dekker Ed.), Amazon, New York, p.541-548.

4. Cerkvenik V, Doganoc DZ, Skubic V, Beek MJ, Keukens HJ. 2001. Thermal and long-term freezing stability of ivermectin residues in sheep milk. Eur Food Res Tech 213: 72-76.

5. Cooper KM, Whelan M, Danaher M, Kennedy DG. 2011. Stability during cooking of anti-helminthic veterinary drug residues in beef. Food Add Contam 28: 155-165.
6. European Commission Regulation. 2010. Reg. No 37 concerning on pharmacologically active substances and their classification regarding maximum residue limits in foodstuffs of animal origin. url http://www.ema.europa. eu/ema/index

7. FIL-IDF $N^{\circ} 040 / 1966$ : Standard method for the count of coliform bacteria in pasteurized milk y No 258/1991: Detection and confirmation of inhibitors in milk and milk products. url http://www.fil-idf.org/public/publicationspage

8. Fthenakis GC, Papadopoulos E, Himonas C. 2005. Effects of three anthelmintic regimes on milk yield of ewes and growth of lambs. J Vet Med 52: 78-82.

9. Harrigan WF, McCance ME. 1976. Laboratory methods in food and dairy microbiology, Academic Press, London, $452 \mathrm{p}$.

10. Juste Jordán R, García A. 1991. Effect of treatment with netobimin on milk production of sheep. Vet Parasit 38 : 173-183.

11. McKellar QA, Benchaoui HA. 1996. Avermectins and milbemycins. J Vet Pharm Ther 19: 331-351.

12. Riviere JE, Spoo JW. 1995. Chemical residues in tissue of food animals. In: Veterinary Pharmacology and Therapeutics (Adams HR Ed), Iowa State Univ. Press, Ames (USA), p.1148-1157.

13. Rose MD, Farrington WH, Shearer G. 1998. The effect of cooking on veterinary drug residues in food: 7. Ivermectin. Food Addit Contam 15: 157-161.

14. Toutain PL, Campan M, Galtier P, Alvinerie M. 1988. Kinetic and insecticidal propieties of ivermectin residues in the milk of dairy cows. $J$ Vet Pharm Ther 11: 288-291. 